\title{
The Correlation of Maternal Childbirth Experience Satisfaction with Postnatal Depression, Anxiety and Stress Scoring
}

\author{
Muna Khaleel Al-kubaisi ${ }^{\text {*1 }}$, Ali S Radeef ${ }^{2}$, Hamizah Ismail ${ }^{1}$ \\ ${ }^{1}$ Department of Obstetrics and Gynaecology, College of Medicine, International Islamic University \\ Malaysia Medical Centre \\ ${ }^{2}$ Department of Psychiatry, College of Medicine, International Islamic University Malaysia, Medical Centre \\ Corresponding author: Asst. Prof. Dr. Muna Khaleel Alkubaisi; mkubaysi@gmail.com
}

Received 19 June 2019;

Accepted 21 July 2019;

Published 24 July 2019

\begin{abstract}
Aim: To evaluate the relationship of childbirth satisfaction and maternal postnatal emotional disturbances and to explore the socialdemographic factors that affects the maternal childbirth experience. Methods: The study was performed at Hospital Ampuan Afzan in Kuantan, Pahang, Malaysia. All women presented with labour or elective caesarean sections (CS) at term were counselled to participate in the study. A total number of 600 participants were recruited. Elective CS perform in 99 patients and vaginal delivery achieved by 320 mothers, 40 ended by instrumental delivery and 141 went through emergency CS. Patients were interviewed 24 hours postnatal using two questionnaires; childbirth satisfaction questionnaire and DASS21 for psychological assessment. The data were analysed using possible correlation matrix in SPSS 23 version. Results: Pearson correlation test; Satisfaction had an inverse relation with depression scores $(r=-0.14, n=600, p=0.001)$, anxiety $(r$ $=-0.125, n=600)(p=0.002)$, and stress $(r=-0.116, n=600, p=0.005)$. Independent sample $t$-test; Women with satisfaction score below the mean $(<66.01)$ have higher depressive mood $(4.66 \pm 5.31)$ than women with satisfaction score above the mean $(\geq 66.01)(3.69 \pm 5.40)(p<0.03)$. The same significant relation was seen with stress score $(8.91 \pm 7.27$ and $7.78 \pm 7.01$ respectively) $(p<0.05)$ but not with anxiety. Mothers who deliver first child (Primiparous) have lower satisfaction than women with previous delivery experience (Multiparous) $(64.99 \pm 6.31$ and $66.70 \pm$ 6.45 respectively) $(p<0.05)$ and women with neonates admitted to neonatal intensive care $(65.08 \pm 6.52$ and $66.70 \pm 6.42$ respectively) ( $p<$ $0.05)$ are more liable to have dissatisfaction. Women delivered by elective caesarean section (CS) or instrumentation have lower satisfaction score than normal delivery and emergency CS ( $p<0.05)$. Conclusion: Negative psychological background of mothers affects the level of maternal satisfaction post-childbirth. Primiparous mothers are dissatisfied with childbirth as compared with multiparous women. Neonatal admission to the Intensive Care Unit (NICU) negatively affects maternal satisfaction. Mothers with higher education have better satisfaction score.
\end{abstract}

Keywords: Satisfaction, childbirth, depression, anxiety, stress

\section{Introduction}

Childbirth satisfaction is one of the primary factor that reflects the performance of medical institutions ${ }^{[1]}$. Satisfaction is affected by many factors, including maternal psychology ${ }^{[2]}$ maternal sociodemographic background, antenatal preparation and mode of delivery ${ }^{[3]}$. Medical institute`s performance largely affects patient satisfaction, therefore those institutes use different tools to measure this subjective aspect in evaluating their services. In this study, we are exploring the relation between maternal psychology that is reflected by depression, anxiety and stress level, and the satisfaction score in the postnatal period. Childbirth satisfaction questionnaire (CEQ) is a tool used in measuring women's satisfaction after delivery ${ }^{[4]}$. It consists of 22 items to evaluate patient own capacity, professional support, perceived safety and patient participation with maximum score of 88 , the questionnaire was translated and validated to the Malaysian language (Bahasa Malaysia) and thus could be applied to the local population ${ }^{[5]}$.

Maternal emotional disturbances, namely; depression, anxiety and stress are common symptoms that peak in the peripartum period ${ }^{[6]}$. Those adverse emotions may influence the level of satisfaction ${ }^{[7]}$. Many researchers studied the impact of postpartum depression and its negative effect on mother and new born ${ }^{[8]}$. However, these symptoms are considered treatable by reducing the risk factors using cognitive-behavioural therapy and interpersonal therapy ${ }^{[9]}$.

The depression, Anxiety and Stress Scale - 21 (DASS-21) is one of these questionnaires consists of 21 questions constructed to evaluate depression, anxiety and stress and had been used in postnatal period ${ }^{[10]}$. It was also translated to the Malaysian language and validated in the community ${ }^{[11]}$. The two 
questionnaires were used to evaluate maternal childbirth satisfaction and maternal psychological disturbances at 24 hours postnatal.

Maternal emotions are affected by other factors such as mode of delivery ${ }^{[12]}$ where, pregnancy can end up by spontaneous vaginal delivery or as an elective caesarean section (CS). In some instances, unexpected events might take place during vaginal delivery and end up by instrumental delivery or emergency CS. Changes in the plan of delivery can contribute to dissatisfactions with the birth experience ${ }^{[13]}$.

Other factors that influence maternal satisfaction may include the economic and educational status, neonatal admission to NICU ${ }^{[14]}$. Prolonged labour reported as a risk factor for developing posttraumatic stress disorder ${ }^{[15]}$. Similarly for unplanned events like instrumentation and emergency $\mathrm{CS}^{[16]}$. Identifying the factors that affect satisfaction can help with planning strategies for early intervention to improve maternal impression regarding childbirth experience before it affects the future feelings ${ }^{[17]}$. This will decrease the cost of late interventions in the public medical institutions and improve the contentment of patients in the private sectors $^{[18]}$.

\section{Materials and Methods}

A prospective cohort study conducted on a sample of 600 pregnant women presented for delivery. Elective CS was performed in 99 women and 501 went through a trail of vaginal delivery. The study was approved by IIUM Research Ethical Approval Committee (IREC), Clinical Research Centre (CRC) and National Medical Research Register (NMRR). Informed consent was obtained from the participants after explaining the nature of the study. All participants were ensured of the confidentiality and that the information gathered was only used for research purposes. Postnatal women who are able to give informed consents and communicate in Bahasa Malaysia were counselled to participate in the study on voluntary bases.

Socio-demographic characteristics data were collected from the patients. Normal vaginal delivery achieved by 320 mothers, 40 ended by instrumental delivery and 141 went through emergency CS. The Childbirth Experience Questionnaire (CEQ) applied to evaluate the level of satisfaction after 24 hours post-delivery. The severity of depression, anxiety and stress symptoms were assessed by using the self-rating Bahasa Malaysia version of the Depression Anxiety and Stress Scales (DASS-21). Both questionnaires had been translated and validated ${ }^{[5,11]}$.

The collected data were keyed into a database and cleaned before analysis. The statistical package for social sciences (SPSS) software version 23.0 was used for both descriptive and inferential analysis. Univariate statistics such as mean values, standard deviations, frequencies and proportion percentages were derived for continuous and categorical variables respectively. Pearson correlation matrix and paired sample ' $t$ ' test were used to determine the maternal satisfaction against depression, anxiety and stress encountered during the child birth. Strength of association between the variables in the study was validated by correlation coefficient (r). All tests were two-tailed with significance defined at $95 \%$ confident interval $(\mathrm{p}<0.05)$.

\section{Results}

Socio-demographic data showed no significant difference in the mean of income and education, but there is a difference in age group underwent instrumentation. Babies delivered by instrumentation and emergency CS have significantly high admission rate to NICU. Prevalence of clinically significant depression, anxiety and stress were $0.92 \%, 9.8 \%$ and $2.23 \%$ respectively. The influence of different mode of delivery on the level of satisfaction on the volunteers showed overall satisfaction mean score of 66.01 out of 88 (maximum score for full satisfaction) which gives a $75 \%$ satisfaction of delivery service. There were significant differences in satisfaction score between women delivered by normal vaginal delivery compared to elective CS and instrumentation, however, no significant difference in the mean satisfaction score of women delivered by emergency CS as compared to normal vaginal delivery (Table 1 ).

Table 1: Socio-demographic characteristic and mean level of satisfaction, depression, anxiety and stress

\begin{tabular}{|c|c|c|c|c|}
\hline & $\begin{array}{c}\text { NVD } \\
(\mathrm{N}=320) \\
\text { Mean } \pm \text { SD }\end{array}$ & $\begin{array}{c}\text { Instrumentation } \\
(\mathrm{N}=40) \\
\text { Mean } \pm \text { SD }\end{array}$ & $\begin{array}{c}\text { Emergency C.S } \\
(\mathrm{N}=141) \\
\text { Mean } \pm \text { SD }\end{array}$ & $\begin{array}{c}\text { Elective C.S } \\
(\mathrm{N}=99) \\
\text { Mean } \pm \text { SD }\end{array}$ \\
\hline Age/year & $29.52 \pm 5.65$ & $27.70 \pm 4.95^{*}$ & $30.01 \pm 5.12$ & $29.90 \pm 4.83$ \\
\hline Satisfaction score & $67.14 \pm 7.63$ & $65.00 \pm 6.17 *$ & $65.70 \pm 7.36$ & $64.85 \pm 7.35^{*}$ \\
\hline Depression & $3.33 \pm 4.97$ & $3.68 \pm 5.76$ & $2.80 \pm 4.11^{*}$ & $3.57 \pm 5.04$ \\
\hline Anxiety & $6.36 \pm 6.38$ & $6.73 \pm 7.63^{*}$ & $5.60 \pm 5.88$ & $6.52 \pm 6.30$ \\
\hline \multirow[t]{2}{*}{ Stress } & $6.63 \pm 6.56$ & $7.36 \pm 8.75^{*}$ & $6.27 \pm 5.95$ & $6.95 \pm 7.31$ \\
\hline & \multicolumn{4}{|c|}{ Number $(\%)$} \\
\hline \multicolumn{5}{|l|}{ Income: } \\
\hline$<5000 \mathrm{RM}$ & $271(84.68 \%)$ & $34(85.00 \%)$ & $123(87.23 \%)$ & $79(79.79 \%)$ \\
\hline$>5000 \mathrm{RM}$ & $49(15.31 \%)$ & $6(15.00 \%)$ & $18(12.76 \%)$ & $20(20.20 \%)$ \\
\hline \multicolumn{5}{|l|}{ Education: } \\
\hline Primary & $16(5.00 \%)$ & $3(7.50 \%)$ & $14(9.93 \%)$ & $3(3.03 \%)$ \\
\hline Secondary & $186(58.13 \%)$ & $23(57.50 \%)$ & $87(61.70 \%)$ & $56(56.57 \%)$ \\
\hline Higher & $118(36.87 \%)$ & $14(35.00 \%)$ & $40(28.37 \%)$ & $40(40.40 \%)$ \\
\hline NICU Admission & $27(8.43 \%)$ & $11(27.50 \%)^{*}$ & $32(22.69 \%)^{*}$ & $14(14.14 \%)$ \\
\hline \multicolumn{5}{|l|}{ Parity: } \\
\hline Primigravida & $37(11.56 \%)$ & $6(15.00 \%)$ & $23(16.31 \%)$ & $7(7.07 \%)^{*}$ \\
\hline Multigravida & $283(88.43 \%)$ & $34(85.00 \%)$ & $118(83.69 \%)$ & $92(92.93 \%)$ \\
\hline
\end{tabular}


No difference in satisfaction score between different age groups, income, gestational age, but there are higher satisfaction score in multiparous patients comparing to primiparous. Women with a high educational level have a high score of childbirth satisfaction. Women with neonatal admission to NICU have low satisfaction score. (Table 2).

Table 2: Satisfaction score with socio-demographic characteristics.

\begin{tabular}{|c|c|}
\hline $\begin{array}{c}\text { Socio-demographic } \\
\text { characteristics }\end{array}$ & $\begin{array}{c}\text { Maternal childbirth } \\
\text { satisfaction score }\end{array}$ \\
\hline Age & \\
\hline $15-35$ & $66.53 \pm 6.53$ \\
$>35$ & $66.47 \pm 6.01$ \\
\hline Income & \\
\hline <5000 & $66.46 \pm 6.31$ \\
$>5000$ & $66.73 \pm 7.26$ \\
\hline Parity & \\
\hline Primi & $64.99 \pm 6.31^{*}$ \\
multip & $66.70 \pm 6.45$ \\
\hline Educational level & $65.00 \pm 5.68$ \\
\hline Primary & $66.38 \pm 6.42$ \\
Secondary & $67.00 \pm 6.60^{*}$ \\
\hline Higher education & \\
\hline YES & $65.08 \pm 6.52^{*}$ \\
\hline NO & $66.70 \pm 6.42$ \\
\hline
\end{tabular}

Pearson correlation coefficient used to assess the relation between childbirth satisfaction score and depression, anxiety, and stress symptom scores. A negative correlation between satisfaction and depression scores were observed $(\mathrm{r}=-0.14, \mathrm{n}=600, \mathrm{p}=0.001)$, the same trend was noticed with anxiety $(\mathrm{r}=-0.125, \mathrm{n}=600, \mathrm{p}=$ $0.002)$, and stress $(r=-0.116, n=600, p=0.005)$. (Figure 1,2 and $3)$.

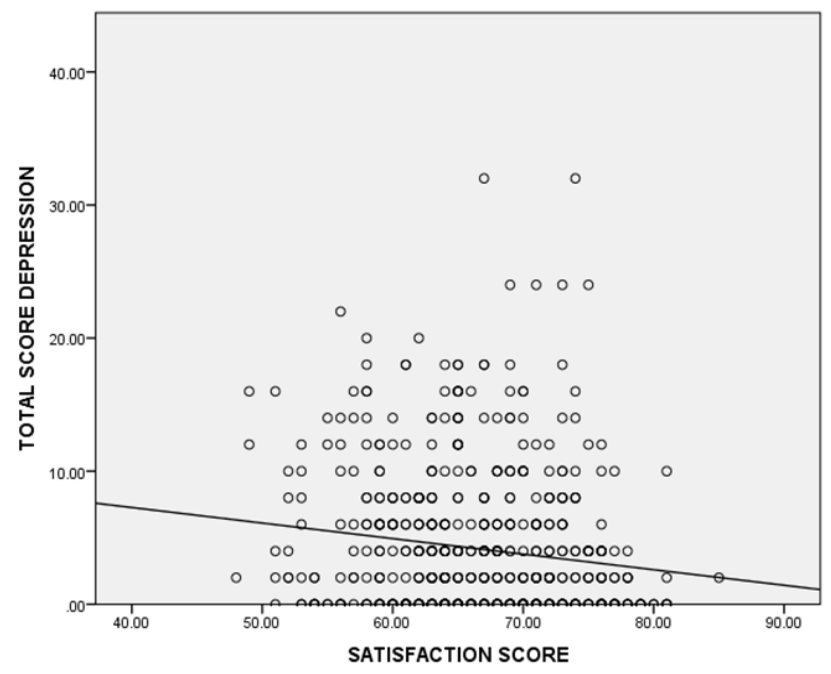

Figure 1: Correlation of satisfaction with depressive symptoms score.

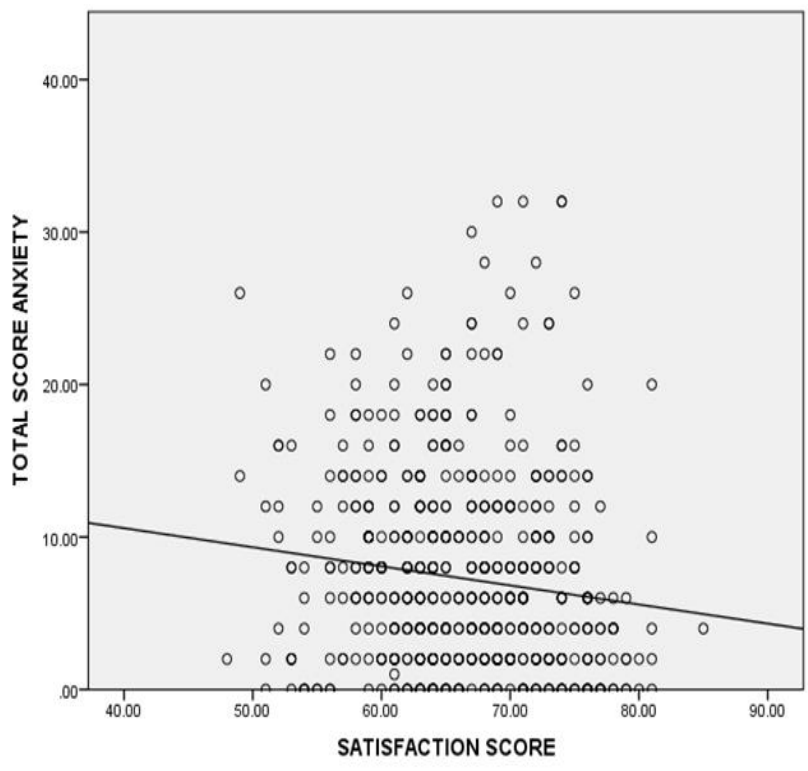

Figure 2: Correlation of satisfaction with anxiety score.

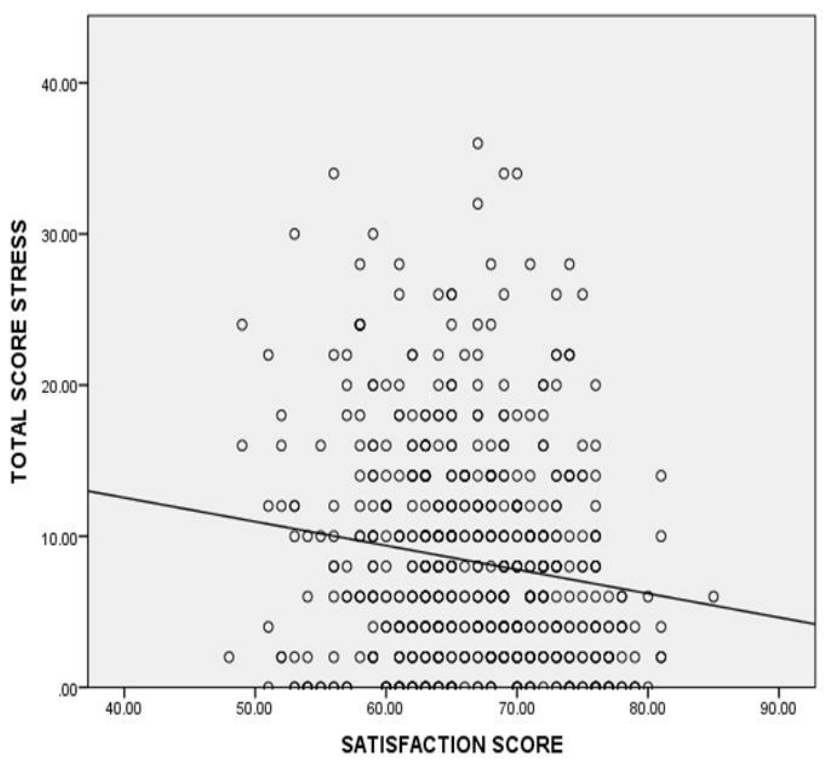

Figure 3: Correlation of satisfaction with stress score.

Using an independent samples t-test, we further analysis the relation between satisfaction score and maternal psychology scoring by dividing the studied population into two groups according to mean satisfaction score. The first group were women scored above the mean and a second group were women scored below the mean; Table 3 shows women with a satisfaction score below the mean have significant differences in depression and stress mean score than those with satisfaction score above the mean with $p<0.05$ while there was no difference in the anxiety score in both groups. (Table 3).

Table 3: The relation between level of satisfaction and maternal emotions

\begin{tabular}{|c|c|c|c|c|c|c|}
\hline Satisfaction & Depression Mean & p value & Anxiety Mean & p value & Stress Mean & p value \\
\hline$\geq 66.01$ & $3.69 \pm 5.40$ & \multirow[t]{2}{*}{0.03} & $6.92 \pm 6.71$ & \multirow[t]{2}{*}{ NS } & $7.78 \pm 7.01$ & \multirow[t]{2}{*}{0.05} \\
\hline$<66.01$ & $4.66 \pm 5.31$ & & $7.62 \pm 6.09$ & & $8.91 \pm 7.27$ & \\
\hline
\end{tabular}

\section{Discussion}

In order to improve maternal childbirth satisfaction, one has to evaluate the psychological background of mothers. Maternal psychology should be screened during first antenatal visit for postpartum blue and depression ${ }^{[19]}$. Antenatal classes should be offered to decrease anxiety towards the unknown events that might take place during pregnancy and labour specifically with first time mothers ${ }^{[20]}$. Early screening and counselling, benefits other obstetrical interventions during pregnancy and can prepare the 
women for any unexpected procedures ${ }^{[21,22]}$. Knowledge about events can help in decreasing psychological impact on mother ${ }^{[23]}$. In our study; mothers with higher education showed higher level of satisfaction than mothers with lower education level.

Our results have shown a negative correlation between satisfaction and maternal psychological scoring results. Other researchers support this observation ${ }^{[24]}$. The antenatal screening can pick up the depressive symptoms, stress, and anxiety by applying different questionnaires that can be accompanied by proper counselling to improve the satisfaction throughout labour ${ }^{[25]}$. Unfortunately the ideal tools do not exist yet as shown by meta-analysis studies ${ }^{[26]}$. Screening instruments can pick up pathological level of psychological disturbances to get the benefit of early psychological consultation referrals and follow up ${ }^{[21]}$. In our study we used DASS21 for screening as it was used before by many other studies for postnatal evaluation ${ }^{[26]}$.

Our study shows that patients with low satisfaction have the highest score for depression and stress. In our study the prevalence of clinically significant depression was $0.9 \%$. Previous studies have shown the prevalence of postpartum depression (PPD) with the percentage range between $0.5 \%-60 \%$ globally and between $3.5 \%$ and $63.3 \%$ in Asian region with the minimum PPD of $3.9 \%$ to $22 \%$ based on different mode of delivery and demographic status in Malaysia ${ }^{[27,28,29,30]}$ and maximum PPD value of $36 \%$ to $63.3 \%$ in Pakistan ${ }^{[31,32,33]}$. Ameliorating the depression and stress can help in improving the satisfaction and decrease the incidence of interventions during labour ${ }^{[34]}$. Depression can be aided by coping with pregnancy strategies and decreasing the incidence of antenatal maladaptation coping behaviour $^{[35]}$. Antenatal interventions and education can help in preparing the couples for the upcoming event of paternity. Planning for a clear protocol is also important ${ }^{[21,36]}$.

Stressful factors can be overlooked in the physical environment that surround the patient during labour and most of these factors pass unnoticed by the medical staff. Those factors include; poor communication, noisy-busy environment in the labour room, non participation in decision making and may even include the layout of the labour room ${ }^{[37]}$.

Anxiety can be mitigated by simple physical measures such as massage that is recommended for some high risk cardiac patients ${ }^{[38]}$ or with music for mechanically ventilated patients ${ }^{[39]}$. Antenatal visits to the labour room and the choice of the setting is a good practice to help patient's anxiety ${ }^{[40]}$.

Mode of delivery indirectly influence women's satisfaction with childbirth experience but factors like involvement in decisionmaking, support and effective analgesia appear to be important to improve women's birth experience ${ }^{[41]}$. From our study, women who run through vaginal delivery had the highest satisfaction score followed by women with emergency CS. Significant difference and lower satisfaction was observed with patients underwent the elective CS and instrumentation $(\mathrm{P}<0.05)$. Subjective distress in labour and obstetrical emergencies are important risk factors for post-traumatic stress disorder ${ }^{[42]}$. This observation goes with our results regarding the instrumentation, but not the emergency CS. Literatures considered the planned delivery carry more satisfaction than the unplanned events like the emergency CS, however, our result contradicts with previous reports ${ }^{[13]}$.
Our socio-demographic variable analysis includes; parity, neonatal admission to NICU, maternal age, income and level of education. Most of these factors did not show a significant difference in satisfaction apart from being a primigravida. Some literatures were found evaluating this factor, but few emphasize on that being first time mothers are a risk factor for psychological disturbances or dissatisfaction ${ }^{[43]}$. It is clear that NICU admission is a real issue for mothers to worry about, thus it will affect their childbirth satisfaction $^{[44]}$.

\section{Conclusion}

Maternal childbirth satisfaction is inversely affected by maternal depression, anxiety and stress level. Other factors negatively affect satisfaction level include: delivery via instrumentation or elective $\mathrm{CS}$, being a first time mother and mothers with neonate admitted to the intensive care unit while high educational level associated with positive maternal childbirth satisfaction.

\section{Study Limitation}

There was no antenatal supportive intervention applied to compare the effect of support, explanation and reflection of the positive aspects of labour to improve maternal psychology towards childbirth and measure the effect difference between the two groups.

\section{Precise}

The purpose of this study is to assess the relation between maternal childbirth satisfaction and the triad; depression, anxiety, and stress.

\section{Acknowledgement}

We would like to show our gratitude to the International Islamic University Malysia (IIUM) for providing us the Research Initiative Grant Scheme 15 (RIGS15-080-0080). We thank our colleagues from HTAA that greatly assisted the research and give us the opportunity to run the work at their respective hospital. We would also like to thank all the women who agree to participate in this research.

\section{References}

[1] Boulding W, Glickman SW, Manary MP, Schulman KA, Staelin R. Relationship between patient satisfaction with inpatient care and hospital readmission within 30 days. Am J Manag Care 2011;17(1):41-8.

[2] Strine TW, Kroenke K, Dhingra S, Balluz LS, Gonzalez $\mathrm{O}$, Berry JT, et al. The associations between depression, health-related quality of life, social support, life satisfaction, and disability in community-dwelling US adults. J Nerv Ment Dis 2009;197(1):61-4.

[3] Orange FA de, Passini R, Melo ASO, Katz L, Coutinho IC, Amorim MMR. Combined spinal-epidural anesthesia and non-pharmacological methods of pain relief during normal childbirth and maternal satisfaction: a randomized clinical trial. Rev Assoc Med Bras (1992) 2012;58(1):112-7.

[4] Dencker A, Taft C, Bergqvist L, Lilja H, Berg M. Childbirth experience questionnaire (CEQ): development and evaluation of a multidimensional instrument. BMC Pregnancy Childbirth 2010;10:81. 
[5] Al-kubaisi MK, Radeef A. Translation and validation study of the malaysian version of the childbirth experience questionnaire - CEQ. Journal of International Dental and Medical Research 2018;11:357-61.

[6] Austin M-PV, Hadzi-Pavlovic D, Priest SR, Reilly N, Wilhelm K, Saint K, et al. Depressive and anxiety disorders in the postpartum period: how prevalent are they and can we improve their detection? Arch Womens Ment Health 2010;13(5):395-401.

[7] Ford E, Ayers S. Stressful events and support during birth: the effect on anxiety, mood and perceived control. J Anxiety Disord 2009;23(2):260-8.

[8] Bell AF, Andersson E. The birth experience and women's postnatal depression: A systematic review. Midwifery [Internet]. 2016;39:112-23. Available from: http://www.sciencedirect.com/science/article/pii/S02666 13816300432

[9] Smith, M.S., \& Segal, J. (2015). Postpartum Depression and the baby blues: Symptoms, treatment, and support for new moms. Retrieved from http://www.helpguide.org/articles/depression/postpartum -depression-and-thebabyblues.htm\#treatment

[10] Norhayati MN, Hazlina NHN, Asrenee AR, Emilin WMAW. Magnitude and risk factors for postpartum symptoms: a literature review. J Affect Disord 2015;175:34-52.

[11] Musa R. Concurrent Validity Of The Depression And Anxiety Components In The Bahasa Malaysia Version Of The Depression Anxiety and Stress Scales (DASS). ASEAN Journal of Psychiatry 2010;12:1-5.

[12] Chalmers B, Kaczorowski J, Darling E, Heaman M, Fell $\mathrm{DB}$, O'Brien $\mathrm{B}$, et al. Cesarean and vaginal birth in canadian women: a comparison of experiences. Birth 2010;37(1):44-9.

[13] Afshar Y, Mei JY, Gregory KD, Kilpatrick SJ, Esakoff TF. Birth plans-Impact on mode of delivery, obstetrical interventions, and birth experience satisfaction: A prospective cohort study. Birth 2018;45(1):43-9.

[14] Lancaster CA, Gold KJ, Flynn HA, Yoo H, Marcus SM, Davis MM. Risk factors for depressive symptoms during pregnancy: a systematic review. Am J Obstet Gynecol 2010;202(1):5-14.

[15] Reynolds JL. Post-traumatic stress disorder after childbirth: the phenomenon of traumatic birth. CMAJ 1997;156(6):831-5.

[16] O'Driscoll K, Meagher D, MacDonald D, Geoghegan F. Traumatic intracranial haemorrhage in firstborn infants and delivery with obstetric forceps. Br J Obstet Gynaecol 1981;88(6):577-81.

[17] Rouhe H, Salmela-Aro K, Halmesmäki E, Saisto T. Fear of childbirth according to parity, gestational age, and obstetric history. BJOG 2009;116(1):67-73.

[18] Mihalopoulos C, Harris M, Henry L, Harrigan S, McGorry P. Is Early Intervention in Psychosis CostEffective Over the Long Term? Schizophr Bull 2009;35(5):909-18.

[19] Kenny, Myers. Obstetrics by Ten Teachers [Internet]. 2017 [cited 2019 Jan 14]. Available from: https://www.crcpress.com/Obstetrics-by-TenTeachers/Kenny-Myers/p/book/9781498744393

[20] Spinelli A, Baglio G, Donati S, Grandolfo ME, Osborn J. Do antenatal classes benefit the mother and her baby? J Matern Fetal Neonatal Med 2003;13(2):94-101.
[21] Andersson L, Sundström-Poromaa I, Wulff M, Aström M, Bixo M. Implications of antenatal depression and anxiety for obstetric outcome. Obstet Gynecol 2004;104(3):467-76.

[22] Kowalcek I, Mühlhoff A, Bachmann S, Gembruch U. Depressive reactions and stress related to prenatal medicine procedures. Ultrasound Obstet Gynecol 2002;19(1):18-23.

[23] Goodman, P., Mackey, M. C., \& Tavakoli, A. S. (2004). Factors related to childbirth satisfaction. Journal of advanced nursing, 46(2), 212-219.

[24] Cohn MA, Fredrickson BL, Brown SL, Mikels JA, Conway AM. Happiness Unpacked: Positive Emotions Increase Life Satisfaction by Building Resilience. Emotion 2009;9(3):361-8.

[25] Mohammad KI, Gamble J, Creedy DK. Prevalence and factors associated with the development of antenatal and postnatal depression among Jordanian women. Midwifery 2011;27(6):e238-245.

[26] Austin M-P, Lumley J. Antenatal screening for postnatal depression: a systematic review. Acta Psychiatr Scand 2003;107(1):10-7.

[27] Mahmud, W.M.R.W., Shariff, S., Yaacob, M.J., 2002. Postpartum depression: a survey of the incidence and associated risk factors among Malay women in Beris Kubor Besar, Bachok, Kelantan. Malaysian Journal of Medical Science 9 (1), 41-48.

[28] Grace, J., Lee, K.K., Ballard, C., Herbert, M., 2001. The relationship between post-natal depression, somatisation, and behaviour in Malaysian Women. Transcultural Psychiatry 38 (1), 27-34

[29] Koo, V., Lynch, J., Copper, S., 2003. Risk of postnatal depression after emergency delivery. Journal of Obstetrics and Gynaecology Research 29 (4), 246-250

[30] Kadir, A.A., Nordin, R., Ismail, S.B., Yaacob, M.J., Mustapha, W.M.R., 2005. Postnatal depression in mothers attending primary care clinics in Kelantan, Malaysia. International Medical Journal 12 (2), 105-109

[31] Kalyani, G.H.S., Saeed, K., Rehman, I.U., Mubbashar, M.H., 2001. Incidence of depressive illness in Pakistani women during postnatal period. Journal of the College of Physicians and Surgeons Pakistan 11 (4), 246-248.

[32] Husain, N., Bevc, I., Husain, M., Chaudhry, I.B., Atif, N., Rahman, A., 2006. Prevalence and social correlates of postnatal depression in a low income country. Archives of Women's Mental Health 9 (4), 197-202.

[33] Rahman, A., Creed, F., 2007. Outcome of prenatal depression and risk factors associated with persistence in the first postnatal year: prospective study from Rawalpindi, Pakistan. Journal of Affective Disorders 100 (1), 115-121.

[34] Fenwick J, Toohill J, Gamble J, Creedy DK, Buist A, Turkstra E, et al. Effects of a midwife psycho-education intervention to reduce childbirth fear on women's birth outcomes and postpartum psychological wellbeing. BMC Pregnancy Childbirth 2015;15:284.

[35] Mahmoud JSR, Staten R, Hall LA, Lennie TA. The relationship among young adult college students' depression, anxiety, stress, demographics, life satisfaction, and coping styles. Issues Ment Health Nurs 2012;33(3):149-56.

[36] Mihelic M, Morawska A, Filus A. Preparing parents for parenthood: Protocol for a randomized controlled trial of 
a preventative parenting intervention for expectant parents. BMC Pregnancy and Childbirth 2018;18.

[37] Applebaum D, Fowler S, Fiedler N, Osinubi O, Robson $\mathrm{M}$. The impact of environmental factors on nursing stress, job satisfaction, and turnover intention. J Nurs Adm 2010;40(7-8):323-8.

[38] Cutshall SM, Wentworth LJ, Engen D, Sundt TM, Kelly RF, Bauer BA. Effect of massage therapy on pain, anxiety, and tension in cardiac surgical patients: a pilot study. Complement Ther Clin Pract 2010;16(2):92-5.

[39] Han L, Li JP, Sit JWH, Chung L, Jiao ZY, Ma WG. Effects of music intervention on physiological stress response and anxiety level of mechanically ventilated patients in China: a randomised controlled trial. J Clin Nurs 2010;19(7-8):978-87.

[40] Hodnett ED, Downe S, Walsh D. Alternative versus conventional institutional settings for birth. Cochrane Database Syst Rev 2012;(8):CD000012.
[41] Spaich S, Welzel G, Berlit S, Temerinac D, Tuschy B, Sütterlin M, et al. Mode of delivery and its influence on women's satisfaction with childbirth. Eur J Obstet Gynecol Reprod Biol 2013;170(2):401-6.

[42] Andersen LB, Melvaer LB, Videbech P, Lamont RF, Joergensen JS. Risk factors for developing posttraumatic stress disorder following childbirth: a systematic review. Acta Obstet Gynecol Scand 2012;91(11):1261-72.

[43] Darvill R, Skirton H, Farrand P. Psychological factors that impact on women's experiences of first-time motherhood: a qualitative study of the transition. Midwifery 2010;26(3):357-66.

[44] Rossman B, Greene MM, Meier PP. The role of peer support in the development of maternal identity for "NICU Moms." J Obstet Gynecol Neonatal Nurs 2015;44(1):3-16. 